\title{
Insuficiencia renal aguda secundaria como manifestación inicial de favismo en un adulto mayor. Caso clínico
}

\author{
DEMETRIO TORRES C. ${ }^{\text {, }}$ MAURICIO CHANDÍA C.
}

\section{Favism presenting as an acute renal failure. Report of one case}

We report a 67-year-old man presenting with abdominal pain of acute onset, pallor, jaundice and behavioral changes after ingestion of fava beans. In the initial evaluation he appeared acutely ill and had resting dyspnea, edema and jaundice. His initial laboratory assessment disclosed azotemia, elevated lactate dehydrogenase levels, a low hemoglobin concentration $(4.9 / \mathrm{dL})$ and a high corrected reticulocyte count $(4,7 \%)$ with negative direct and indirect Coombs' test. The patient was transferred to the ICU, where he received support therapy with hemodialysis, mechanical ventilation, vasoactive drugs and transfusions of packed red cells. The evolution after 1 month was favorable and he was discharged without anemia and with normal renal function. Three months after discharge, the glucose-6-phosphate-dehydrogenase screening study did not demonstrate detectable enzymatic activity.

(Rev Med Chile 2012; 140: 1043-1045).

Key words: Favism; Glucose-6-phosphate; Hemolysis; Jaundice.

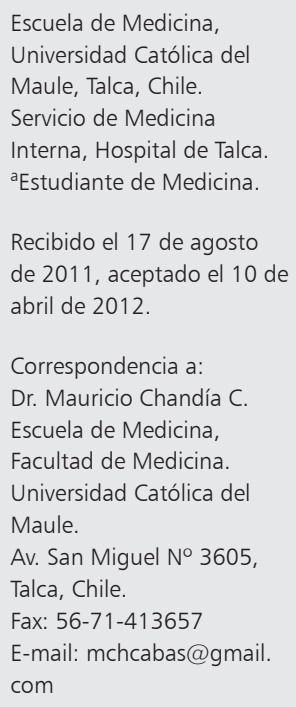

$\mathrm{E}$ 1 déficit de glucosa-6-fosfato-deshidrogenasa (G6FD) es la enzimopatía más común en el ser humano ${ }^{1}$. Corresponde a una enzima intracelular, ubicua; cuya principal función en el eritrocito es protegerlo del estrés oxidativo ${ }^{2}$.

La enzima es parte crucial de la vía de las pentosas $^{3}$, importante en la formación de glutatión, siendo esta la causa de la hemólisis desencadenada por estímulos oxidativos. Especialmente sensible a este déficit es el eritrocito por su condición anuclear'.

La presentación clínica del cuadro es muy variada, siendo descritos 4 cuadros típicos: ictericia neonatal, anemia hemolítica aguda, anemia hemolítica congénita crónica y para un porcentaje importante de portadores el déficit es asintomáti$\mathrm{co}^{5}$. La falla renal vinculada al déficit de G6PD no se encuentra en el espectro clásico, es una entidad rara aunque ha sido descrita ${ }^{6}$.

\section{Caso clínico}

Paciente de 67 años, sexo masculino, con antecedente de epilepsia tónico-clónica sin tratamiento farmacológico actual. No usaba medicamentos, no refería hábitos tóxicos ni alergias a fármacos. Consultó de urgencia por cuadro de 2 días de evolución de dolor abdominal asociado a ictericia, coluria y compromiso del estado general; el cual se habría originado tras consumo de habas. Al examen físico no se encontró evidencias de loxocelismo. No se registraron antecedentes familiares de favismo. Ingresó en falla renal aguda oligúrica, requiriendo soporte dialítico desde su llegada.

En los exámenes de ingreso presentaba hematocrito de $14,1 \%$ con hemoglobina de $4,9 \mathrm{~g} / \mathrm{dL}$, glóbulos blancos 33.000/ $\mu \mathrm{L}$ (fórmula conservada) y leve trombocitopenia $(133.000 / \mu \mathrm{L})$. El recuento de reticulocitos corregido fue de $4,6 \%$. El nitrógeno ureico sanguíneo fue de $125 \mathrm{mg} / \mathrm{dL}$ y creatininemia de $3,47 \mathrm{mg} / \mathrm{dL}$ (producto BUN/ Creatinina 19,2). El sedimento de orina no mostraba hematuria ni cilindros y a la instalación de la sonda Foley se describió salida de orina de color rojizo. La bilirrubina total fue de $5,7 \mathrm{mg} / \mathrm{dL}$; de predominio indirecto $(3,2 \mathrm{mg} / \mathrm{dL})$. El valor de los electrolitos plasmáticos a su ingreso fue de: potasio 
4,9 mEq/L, sodio $137 \mathrm{mEq} / \mathrm{L}$, cloro $99 \mathrm{mEq} / \mathrm{L}$. Gases arteriales: $\mathrm{pH} 7,5, \mathrm{pO}_{2} 139$, bicarbonato 16,4. Los tests de Coombs directo e indirecto fueron negativos.

El paciente fue sometido a transfusión de 9 unidades de glóbulos rojos en días alternos, por lapso de 5 días desde su llegada. El frotis de ingreso negativo para esquistocitos y citometría de flujo negativa a hemoglobinuria paroxística nocturna. Frente a la posibilidad de púrpura trombótico trombocitopénico (PTT) se inició plasmaféresis sin mejoría del cuadro clínico.

Durante su evolución cursó con disfunción hepática y respiratoria, requiriendo ventilación mecánica invasiva por lo cual fue trasladado a UCI. Durante la segunda semana de estadía hospitalaria presentó síndrome de respuesta inflamatoria sistémica secundaria a infección por S. Aureus, se trató con vancomicina; requirió apoyo transitorio con drogas vasoactivas (dobutamina).

Tras aproximadamente 1 mes de hospitalización la ventilación mecánica fue retirada y recuperó diueresis por lo cual fue trasladado a Unidad de Intermedio. Fue dado de alta a los 4 días con valores de nitrógeno ureico $17,2 \mathrm{mg} / \mathrm{dL}$ y creatinina sérica de $1,17 \mathrm{mg} / \mathrm{dL}$.

Dada la posibilidad de sobreestimar la concentración de glucosa-6-fosfato-deshidrogenasa (G6PD) debido a las transfusiones y mayor número de reticulocitos circulantes, es que tres meses después del episodio hemolítico se llevó a cabo el estudio. Este se realizó mediante el método colorimétrico de Tönz y Betke, mostrando actividad enzimática indetectable.

Tabla 1. Principales funciones de las moléculas de NADPH y Ribosa en el metabolismo ${ }^{4}$

\begin{tabular}{|ll|}
\hline NADPH & Ribosa \\
\hline Reacciones biosintéticas & Producción de coenzimas \\
Producción de glutatión & Replicación de ácidos nucleicos \\
Estabilidad de catalasa & División celular \\
Resistencia a estrés oxidativo & \\
\hline
\end{tabular}

\section{Discusión}

La glucosa-6-fosfato-deshidrogenasa es una enzima intracelular, ubicua ${ }^{4}$, cuyo principal rol es la protección del eritrocito frente al estrés oxidativo (Tabla 1). Su deficiencia es el trastorno heredable más común en el hombre, presentándose típicamente en varones jóvenes ${ }^{6}$.

Existe una gran cantidad de sustancias descritas como desencadenantes de hemólisis en pacientes con déficit de G6PD (Tablas 2 y $3)^{7}$. En las variantes más frecuentes de esta enfermedad los síntomas se inician en forma de crisis hemolíticas a edades tempranas ${ }^{8}$. Desde este punto de vista, considerando la edad de nuestro paciente, es notorio que no haya desarrollado previamente este tipo de crisis.

La falla renal aguda desarrollada como producto de una crisis hemolítica por favismo es una entidad clínica rara. El origen de esta complicación estaría en el efecto tóxico sobre la célula tubular de los pigmentos de hemoglobina libre en el plasma que es filtrada por el riñón'.

El diagnóstico diferencial incluye varias causas de nefrotoxicidad asociada a pigmentos. El loxocelismo produce nefrotoxicidad por hemoglobinuria en casos de afectación sistémica ${ }^{9}$, pero se puede descartar porque no existe el hallazgo de las lesiones cutáneas características ni el antecedente de la mordedura de araña. La hemoglobinuria paroxística nocturna puede desencadenar crisis hemolíticas intravasculares masivas (como en este caso), pero se asocia a ausencia de marcación para CD55 Y CD59 $9^{10}$, descartada en la citometría de flujo de sangre periférica.

Por su parte, púrpura trombótico trombocitopénico (PTT), puede presentar hasta en

Tabla 2. Agentes desencadenantes de hemólisis en deficiencia de G6PD?

\begin{tabular}{|ll|}
\hline Factor desencadenante & Mecanismo \\
\hline Fármacos oxidantes & Formación de $\mathrm{H}_{2} \mathrm{O}_{2}$ al interaccionar con hemoglobina \\
Habas, berros y otros alimentos & $\begin{array}{l}\text { Contienen divicina, isouramilo y convencina que aumentan el gluta- } \\
\text { tión oxidado }\end{array}$ \\
\hline Infecciones (neumonía bacteriana, hepatitis aguda) & Estrés oxidativo, acidosis metabólica \\
Cetoacidosis diabética & Acidosis metabólica \\
\hline
\end{tabular}


Favismo con insuficiencia renal aguda - D. Torres et al

Tabla 3. Fármacos con efecto oxidante que pueden ocasionar crisis hemolíticas en déficit de G6PD

\begin{tabular}{|c|c|c|c|}
\hline & Asociación definida & Asociación posible & Asociación dudosa \\
\hline Antimaláricos & $\begin{array}{l}\text { Primaquina } \\
\text { Pamaquina }\end{array}$ & Cloroquina & $\begin{array}{l}\text { Mepacrina } \\
\text { Quinina }\end{array}$ \\
\hline Sulfonamidas & $\begin{array}{l}\text { Sulfanilamida } \\
\text { Sulfacetamida } \\
\text { Sulfapiridina } \\
\text { Sulfametoxazol }\end{array}$ & $\begin{array}{l}\text { Sulfadimidina } \\
\text { Sulfasalazina } \\
\text { Glibenclamida }\end{array}$ & $\begin{array}{l}\text { Aldesulfona } \\
\text { Sulfadiazina } \\
\text { Sulfafurazol }\end{array}$ \\
\hline Sulfonas & Dapsona & & \\
\hline Antipiréticos o analgésicos & Acetanilida & Ácido acetilsalićlico & $\begin{array}{l}\text { Paracetamol } \\
\text { Fenacetina }\end{array}$ \\
\hline Otros fármacos & $\begin{array}{l}\text { Ácido nalixídico } \\
\text { Niridazol } \\
\text { Metiltionino } \\
\text { Fenazopiridina } \\
\text { Cotrimoxazol }\end{array}$ & $\begin{array}{l}\text { Ciprofloxacino } \\
\text { Cloranfenicol } \\
\text { Análogos vitamina K } \\
\text { Ácido ascórbico } \\
\text { Mesalazina }\end{array}$ & $\begin{array}{l}\text { Ácido aminosalicílico } \\
\text { Doxorrubicina } \\
\text { Probenecid } \\
\text { Dimercaprol }\end{array}$ \\
\hline Otros químicos & Naftalina & & \\
\hline
\end{tabular}

un tercio de los casos falla renal, pero de patogenia distinta ${ }^{11}$, sin hemoglobinuria con orinas de color rojizo como en nuestro caso. Además se observó que la curva de descenso de lactato deshidrogenasa fue independiente de la plasmaféresis, mostrando su mayor nadir previo al inicio de ésta, sin aumentar tras su suspensión.

Nuestro reporte enfatiza que siendo el déficit de G6PD la enzimopatía del eritrocito más común en el mundo, es importante considerarla como diagnóstico diferencial en todo caso de anemia hemolítica Coombs negativa asociada a falla renal, a pesar de que no existan estudios de prevalencia de esta enfermedad para nuestro país.

\section{Referencias}

1. B. Mehta A, Glucose-6-phosphate dehydrogenase deficiency. Postgrad Med J 1994; 70: 871-7.

2. Frank JE. Diagnosis and management of G6PD deficiency. Am Fam Physn 2005; 72: 1277-82.

3. Cosentino C, Grieco D, Costanzo V. ATM activates the pentose phosphate pathwaypromoting anti-oxidant defence and DNA repair. The EMBO Journal 2011; 30: 546-5.

4. Ramírez-Cheyne J, Zarante I. Deficiencia de glucosa-6- fosfato deshidrogenasa: situación actual, su relación con malaria y estrategias para calcular su prevalencia. Univ Med Bogotá (Colombia) 2009; 50 (1): 58-76.

5. Bersey M. The epidemiology of favism. Bull World Health Organ 1973; 48 (1): 1-13.

6. Luzzato L. Anemias Hemolíticas: Harrison Principios de Medicina Interna. Fauci A, Braunwald E, Kasper D, Hauser S, Longo D, Jameson J, et al. Editorial Interamericana Mc. Graw-Hill, 17a edición, 2009. pp: 652-62.

7. García MJ, Salvatierra MG, Morado M, Hernández F. Anemias hemolíticas congénitas. Medicine 2008; 10 (20): 1344-5.

8. Lau HK, Li CH, Lee AC. Acute massive haemolysis in children with glucose-6-phosphate dehydrogenase deficiency. Hong Kong Med J 200; 12 (2): 149-51.

9. Schenone H. Cuadros tóxicos producidos por mordeduras de araña en Chile: latrodectismo y loxoscelismo. Rev Med Chile v. 131 n. 4 Santiago abr. 2003.

10. Arruda MM, Rodrigues CA, Yamamoto M, Figueiredo MS. Hemoglobinúria paroxística noturna: da fisiopatologia ao tratamento. Rev Assoc Med Bras 2010; 56 (2): 214-21.

11. Dierkes F, Andriopoulos N, Sucker C, Kuhr K, Hollenbeck M, Hetzel GR, et al. Indicators of acute and persistent renal damage in adult thrombotic microangiopathy. PLoS One 2012; 7 (1). 